Thorax, 1979, 34, 629-636

\title{
Mixed malignant tumour of the lung
}

\author{
C W EDWARDS, ALISON M SAUNDERS, AND F COLLINS
}

From the Departments of Pathology and Thoracic Surgery, East Birmingham Hospital, Birmingham B9 5ST, UK

\begin{abstract}
A mixed malignant tumour of the lung intermediate in type between pulmonary blastoma and carcinosarcoma is described. The epithelial component consisted of squamous carcinoma, undifferentiated carcinoma, and clefts lined by bland epithelial cells. The supporting stroma was composed of pleomorphic sarcoma, fibrosarcoma, chondrosarcoma, osteosarcoma, and indeterminate mesenchymal tissue. The tumour was removed surgically, but the patient died postoperatively with rapidly developing multiple bony and soft tissue metastases. Subcutaneous metastases showed the appearance of poorly differentiated pleomorphic sarcoma. Published reports of mixed malignant lung tumours are reviewed.
\end{abstract}

Lung neoplasms that contain malignant connective tissue and epithelial elements may be classified into three subgroups-namely, carcinosarcomas, pulmonary blastomas, and "transitional" tumours (Davis et al, 1972). Carcinosarcomas are the least rare, and consist of islands of welldifferentiated squamous carcinoma or adenocarcinoma in a stroma of malignant spindle cells, which sometimes shows osseous or chondroid foci. They were first recognised in the early years of this century (Kika, 1908; Saltykow, 1914). Pulmonary blastomas (Spencer, 1961) or embryomas (Barnard, 1952) have a remarkable resemblance to fetal lung even at an ultrastructural level, with epithelial islands and tubules in a pleomorphic spindle cell stroma. The transitional variant, which shows the features of both blastoma and carcinosarcoma, was first described by Davis et al (1972). We describe a case of the latter type of tumour in which there was a wide spectrum of mesenchymal and epithelial malignancy. The pathology, histogenesis, and classification of mixed malignant pulmonary tumours is discussed, and the relevant published reports are reviewed.

\section{Case report}

A 61-year-old confectioner presented in August 1977 with an eight-week history of non-productive cough, ankle swelling, and weight loss. He had had no serious illnesses in the past, and smoked two ounces $(56 \mathrm{~g})$ of pipe tobacco a week. He had mild ankle oedema and finger clubbing. A few crackles were heard at the left base. A chest radiograph showed a large, well-defined mass in the left lower zone and prominence of the left hilum. Results of haematological and biochemical tests were normal. At bronchoscopy there was narrowing of the main lower lobe bronchus on the left side. A biopsy showed normal bronchial mucosa and cartilage.

At thoracotomy four weeks later a mass was found occupying most of the left lower lobe. Lymph nodes at the hilum and in the pulmonary ligament were enlarged. A routine left pneumonectomy was carried out.

Eight days after operation the patient began to complain of pain in the left thigh. A hard, tender, fusiform swelling was found in the quadriceps and a hard, rounded nodule over the lower end of the tibia. Over the next seven days several nodules appeared in the subcutaneous tissues of the lower legs and left upper chest. The nodules in the legs appeared to be fixed to underlying bone, and radiographically the periosteum of the right femur and left tibia and fibula was unevenly raised, with underlying deposits showing partial calcification. The patient died 17 days after operation. His relatives were unwilling to allow necropsy, but permission was given to examine the secondary deposits in the legs.

\section{Pathology}

The pneumonectomy specimen consisted of a collapsed upper lobe and a distended lower lobe. Lymph nodes at the hilum were enlarged up to $2 \mathrm{~cm}$ in diameter. On sectioning, the lower lobe 
was almost completely replaced by a roughly spherical tumour $11 \mathrm{~cm}$ in diameter, with a welldefined and partially encapsulated periphery. Its cut surface was lobular and yellow-white with foci of calcification, haemorrhage, and necrosis. Segmental bronchi were stretched over its surface, but the tumour did not appear to have a bronchial origin.

Histologically, the tumour was of the transitional type, showing the features of both carcinosarcoma and pulmonary blastoma. There was, however, wide variation in the proportions and differentiation of the epithelial and mesenchymal elements, so that some parts consisted of pure carcinoma and others of pure sarcoma of various types.

In the carcinosarcomatous areas (fig 1) much of the epithelial component consisted of islands of well-differentiated, keratinising squamous cells with only moderate numbers of mitotic figures. Sometimes the edges of these islands were illdefined and merged with the adjacent sarcomatous stroma. An unusual feature was the occasional presence of acinar structures lined by small, uniform cells lying among the squamous cells. Where the squamous cells were less well differentiated, the islands were irregular and smaller, and again there was merging of epithelium and stroma. At other sites the epithelial element was frankly adenocarcinomatous and was composed mainly of $\frac{\overrightarrow{\vec{P}}}{\frac{\overrightarrow{0}}{0}}$ acini lined by columnar and cuboidal cells. These $\frac{\square}{\circ}$ acini were sometimes less well defined, and here $\overline{\bar{n}}$ again there appeared to be merging of epithelium and stroma (fig 2).

The stroma around both the squamous and os adenocarcinomatous foci consisted mainly of $\vec{\circ}$ sheets of plump, spindle, and oval cells with $\overrightarrow{\vec{H}}$ pleomorphic, vesicular nuclei and moderate $\vec{\rho}$ numbers of mitotic figures, but sometimes, $\vec{\overrightarrow{ }}$ adjacent to squamous islands it was composed of $\vec{x}$ bland fibrous tissue, so that appearances were those of a pure squamous carcinoma.

In the areas of the tumour that resembled pulmonary blastoma there were well-defined, often branching clefts lined by a single or sometimes multiple layer of bland cuboidal cells. These were surrounded by poorly differentiated oval and spindle cells or indeterminate mesenchymal tissue. In other places the clefts were replaced by solid or partly canalised masses of poorly differentiated $\overrightarrow{0}$ oval cells displaying extensive mitotic activity (fig 3). These latter structures were surrounded by a halo of oedematous connective tissue, and were thus separated from the adjacent stroma

Some parts of the tumour contained little or no epithelial element, and consisted of pure sarcoma that was often of an indeterminate myxoid type with stellate cells in a mucoid background. In

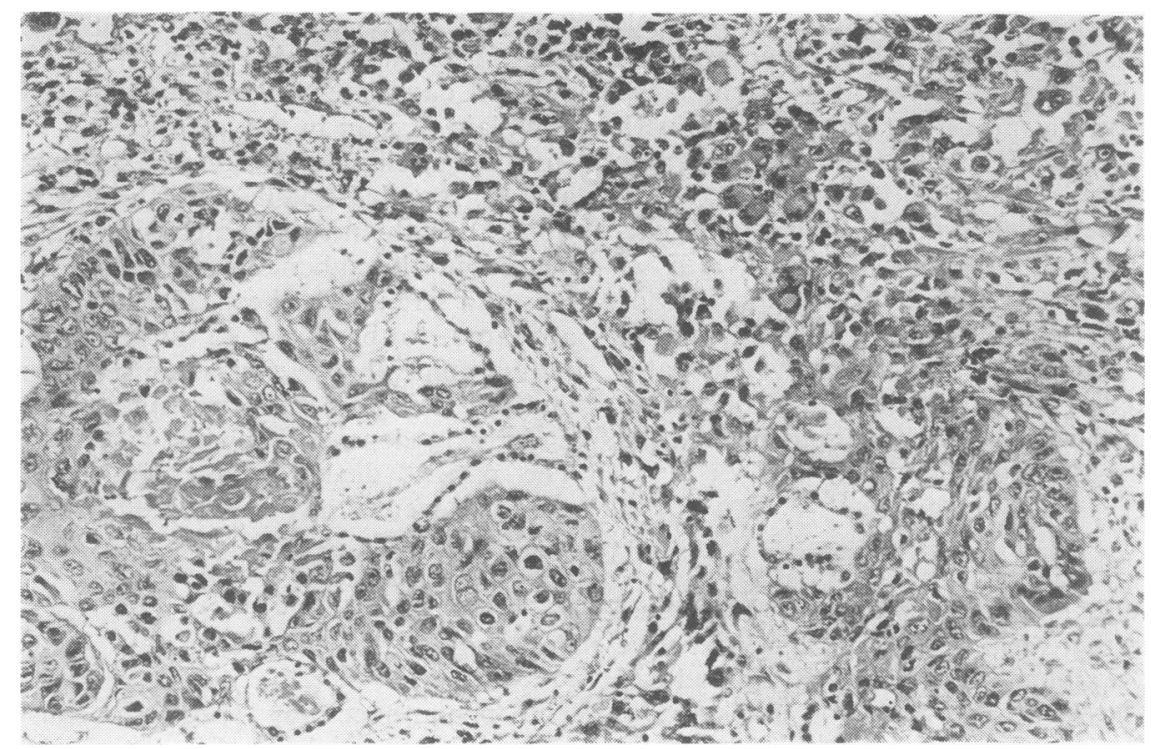

Fig 1 Two foci of well-differentiated squamous carcinoma containing acinar structures lined by small cuboidal cells. On left epithelial tissue merges with sarcomatous stroma. Haematoxylin and Eosin $\times 75$ (original magnification). 


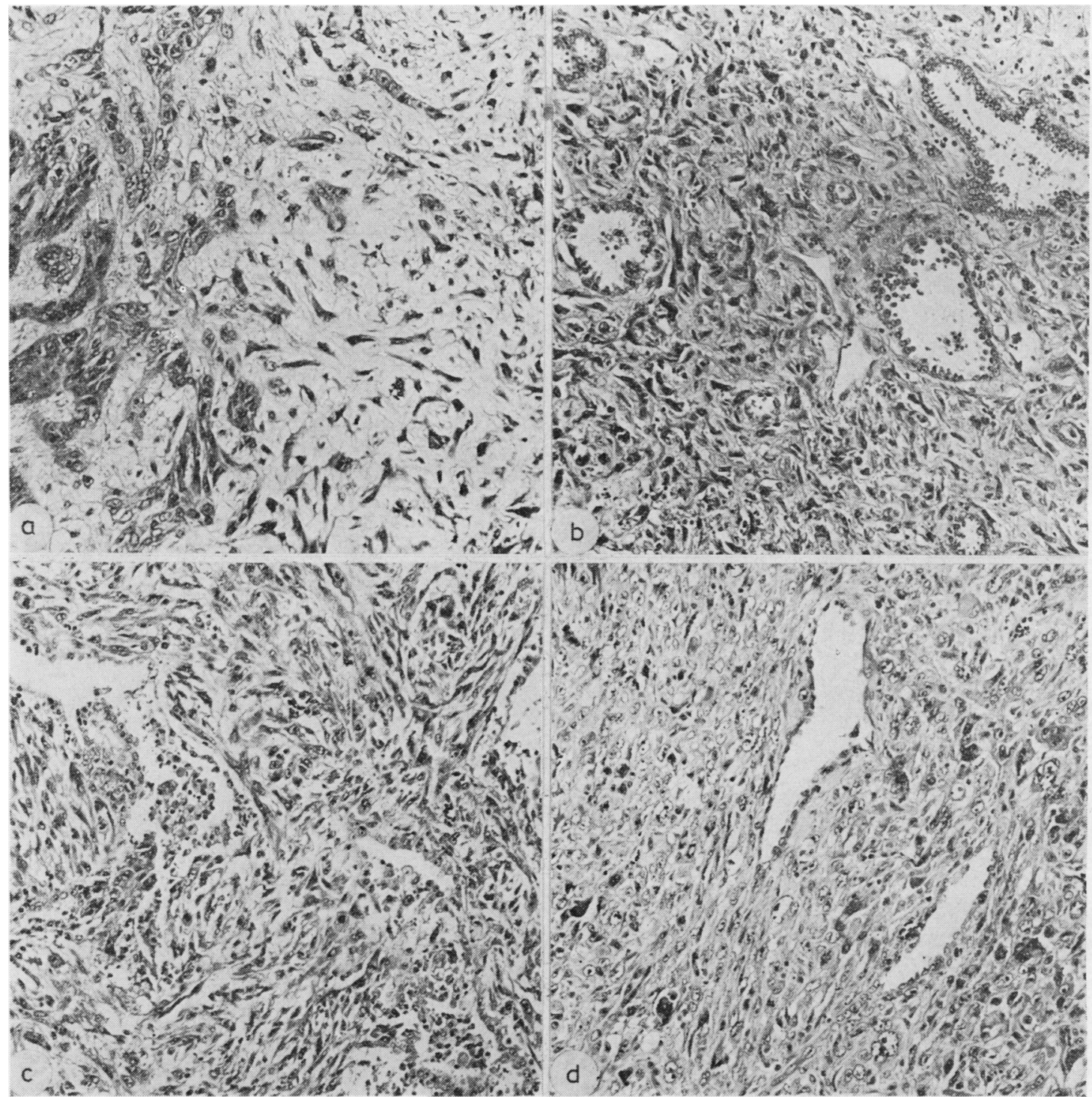

Fig 2 (a) Foci of squamous carcinoma merging with stroma. Epithelial cells are less well differentiated than in fig 1. (b) Foci of adenocarcinoma lying in a sarcomatous stroma. (c) Poorly defined adenocarcinomatous acini merging with adjacent stroma. (d) Well-defined clefts lined by flattened cells lying in a sarcomatous stroma. $H$ and $E \times 100$ (original magnification).

other areas there was frank fibrosarcoma and sometimes foci of osteosarcoma or chondrosarcoma (figs 3 and $4 a$ ).

No tumour deposits were found in hilar lymph nodes or at the bronchial resection line. Subsequent examination of the subcutaneous secondary deposits showed only poorly differentiated, pleomorphic sarcoma. No epithelial component was present (fig $4 b$ ).

\section{Discussion}

Mixed malignant tumours of the 'ung are rare, and their histogenesis is obscure and controversial. The most frequently encountered neoplasm of this type is the carcinosarcoma, which was first described in 1908 by Kika. Although its existence was denied at one time (Saphir and Vass, 1938), it is now generally accepted as a definite entity. and 

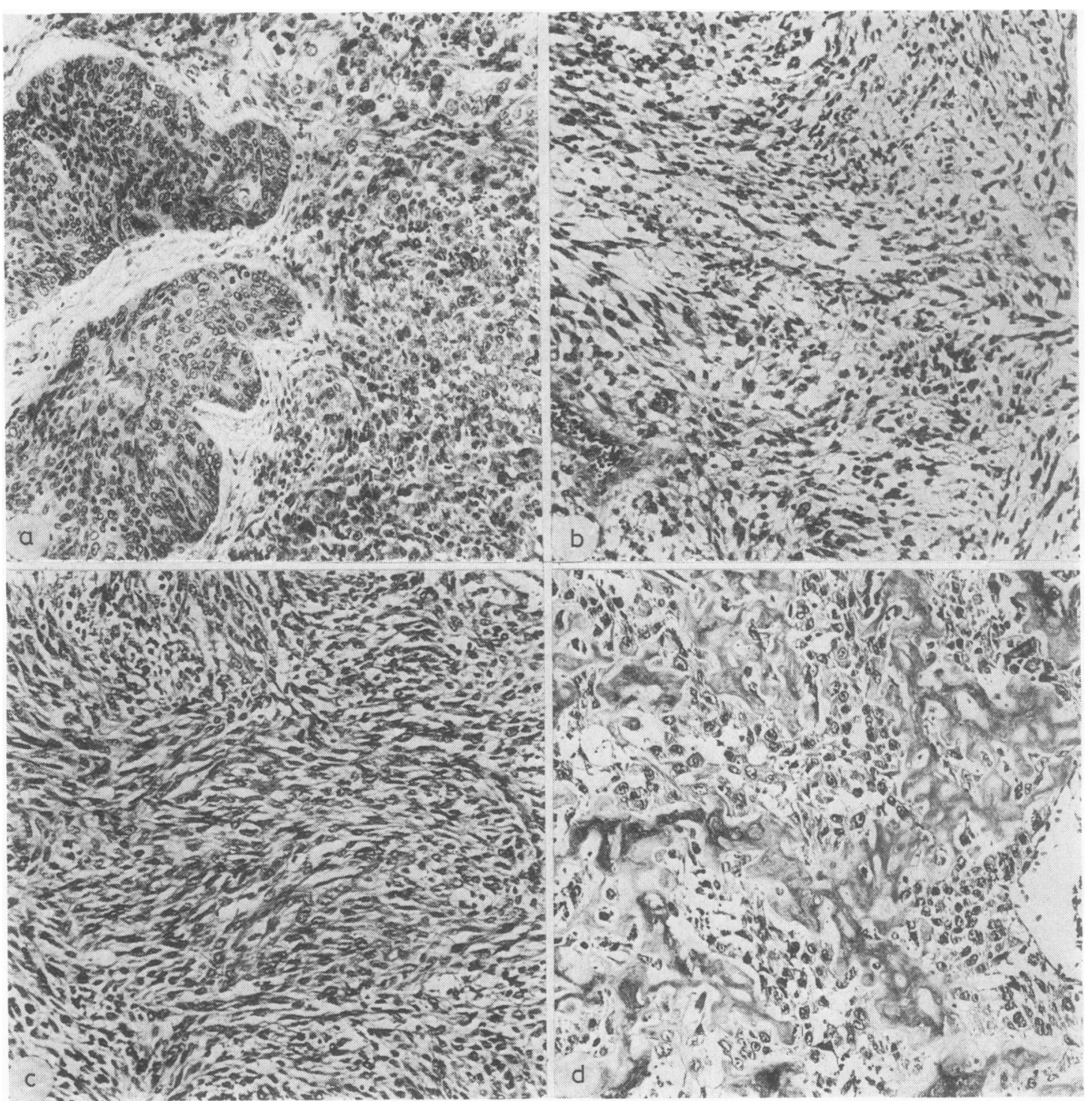

Fig 3 (a) Poorly differentiated epithelial islands with a halo of oedematous connective tissue in a poorly differentiated sarcomatous stroma. (b) Sarcomatous area consisting of indeterminate myxoid tissue. (c) Area of fibrosarcomatous differentiation. (d) Area of osteosarcomatous differentiation. $H$ and $E \times 100$ (original magnification).

numerous cases have been recorded (Bergmann et al, 1951; Drury and Stirland, 1959; Stackhouse et al, 1969; Kakos et al, 1971; Razzuk et al, 1971; Davis et al, 1972; Diaconită, 1975; Ludwigsen, 1977). This tumour, which is much commoner in men, usually occurs in the 60s and 70s: the youngest recorded case was 35 (Saltykow, 1914). Clinically, in common with other pulmonary or bronchial tumours, the presenting symptoms in- $\mathbb{D}$ clude chest pain, haemoptysis, cough, dyspnoea, pyrexia, and weight loss. There is often a history ${ }_{0}$ of heavy smoking, but carcinosarcomas have also $\frac{P}{\mathbb{Q}}$

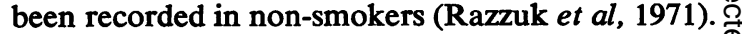

These tumours arise in the peripheral or central $\stackrel{\perp}{\circ}$ parts of the lungs, and attain a size of $10 \mathrm{~cm}$ or more in diameter. There is no predilection for any 0 


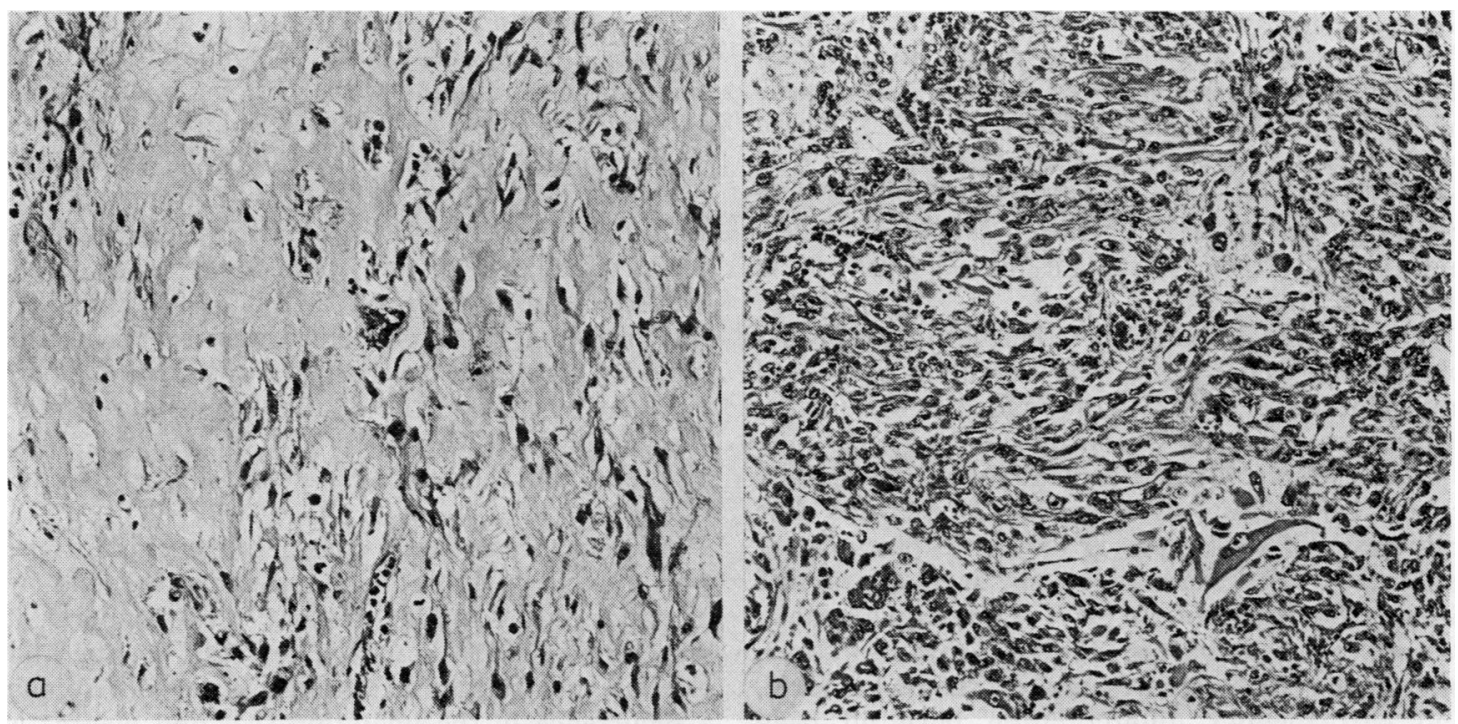

Fig 4 (a) Area of chondrosarcomatous differentiation. (b) Subcutaneous secondary deposit that consists of poorly differentiated, pleomorphic sarcoma. No epithelial element is present. $H$ and $E \times 100$ (original magnification).

particular site. Areas of necrosis and cavitation are common, and there may be foci of calcification or ossification. Apparent encapsulation of all or part of the periphery is not unusual. Central tumours characteristically grow along the lumen of a large bronchus, producing a pedunculated mass that may bleed heavily during biopsy (Ludwigsen, 1977).

Histologically, the epithelial component usually consists of islands of well-differentiated squamous carcinoma, but it may consist of anaplastic carcinoma or adenocarcinoma (Stackhouse et al, 1969; Razzuk et al, 1971; Davis et al, 1972). These epithelial islands lie in a spindle cell sarcomatous stroma, which may contain foci of osteoid (Moore, 1961), or myxoid areas (Kakos et al, 1971). In individual tumours the stroma has been described as leiomyosarcomatous (Weaver et al, 1971), fibrosarcomatous (Stackhouse et al, 1969; Chaudhuri, 1971), chondrosarcomatous (Prive et al, 1961), osteosarcomatous (Stackhouse et al, 1969; Ludwigsen, 1977), and "immature" (Stackhouse et al, 1969). The epithelial and connective tissue elements in some areas may blend and merge one into the other (Stackhouse et al, 1969; Chaudhuri 1971; Davis et al, 1972). Secondary deposits, which are often widespread and appear early, may consist of carcinoma, sarcoma, or a mixture of both (Davis et al, 1972).

Most recorded cases were considered to be operable, and for this reason carcinosarcomas, particularly those arising in the central parts of the lung, were believed to grow slowly and metastasise late (Bergmann et al, 1951; Drury and Stirland, 1959). In recent years, however, it has been shown that the five-year survival rate is no better, if not worse than squamous carcinoma, and that the site of origin does not influence the prognosis (Bull and Grimes, 1974; Ludwigsen, 1977).

Pulmonary blastoma is another tumour that must be considered in the present context. It is much rarer than carcinosarcoma, and was first described in 1952 by Barnard, who named it "pulmonary embryoma" because of its resemblance to fetal lung. Spencer described four further cases in 1961 and renamed it "pulmonary blastoma." This type of neoplasm has recently been reviewed by Karcioglu and Someren (1974) and Fung et al (1977). About 40 cases have been reported at the time of writing.

Like the carcinosarcoma, pulmonary blastoma is commoner in men, but it occurs in a younger age group. It is most frequent in the 40 s and 50s, and cases have been reported in children (Pacharee and Parichatikanond, 1972; Iverson and Straehley, 1973; Marsden and Scholtz, 1976). Again, the presentation is the same as other malignant neoplasms of the lung, the commonest symptoms being cough and haemoptysis. Most pulmonary blastomas are peripheral and consist of a single large, roughly spherical, well-encapsulated mass 
that may show areas of haemorrhage and necrosis. An endobronchial component, similar to that seen in carcinosarcoma, has been reported by Stackhouse et al (1969) and Davis et al (1972). There were cystic areas in the cases described by Rao et al (1974) and Kern and Stiles (1976). Multiple bilateral tumours have also been recorded (Bauermeister et al, 1966; Karcioglu and Someren, 1974; Kern and Stiles, 1976).

The epithelial element of the blastoma consists of clefts or glandular tubules lined by single and multiple layers of columnar or cuboidal epithelium. Solid nests and cords or rosettes may also be seen (Marsden and Scholtz, 1976; Fung et al, 1977). Mitoses are often numerous. The cytoplasm of these cells is sometimes vacuolated, and may contain abundant glycogen (Kern and Stiles, 1976; Fung et al, 1977). The stroma usually resembles an immature fibro- or myxo-sarcoma, but giant cells, areas resembling striated muscle, and cartilagenous differentiation have all been described (Karcioglu and Someren, 1974; Rao et al, 1974; McCann et al, 1976). Stackhouse et al (1969) reported foci of osteogenic sarcoma in the stroma of one of their cases. Conflicting views have been expressed about merging of the two components. Stackhouse et al (1969) and Davis et al (1972) found that epithelial and connective tissue did not blend together, whereas other writers (Spencer, 1961; Henry and Keal, 1966; Rao et al, 1974; McCann et al, 1976) specifically mentioned this feature.

The prognosis of pulmonary blastoma is somewhat better than carcinosarcoma. Although about half of the patients reported have died within two years of presentation, there are cases of long survival on record. For instance, one of the cases reported by Kern and Stiles (1976) lived for nine years, and the other, despite five thoracotomies over 19 years for recurrent tumours, was alive and well at the time of writing. Other long surviving cases include those of Parker et al (1966) and Barnard (1952). Unfortunately, there appears to be no correlation between histological appearance and subsequent behaviour.

Transitional tumours, which are not as welldocumented as blastoma and carcinosarcoma, were described by Davis et al in 1972. They reported three cases, one in a woman of 61 , and the other two in men aged 58 and 65 . The two men had been heavy cigarette smokers. All the tumours were relatively small, the largest measuring $5 \times 2 \times 2 \mathrm{~cm}$, and all had an endobronchial pattern of growth. During the operation in one case tumour broke away from the bronchial wall and became impacted in the main bronchus of the opposite lung.
The epithelial element showed a variety of $\frac{?}{0}$ features. There were islands of well-differentiated $\underline{ }$ epidermoid carcinoma with foci of keratinisation. In other areas the epithelial component consisted $\stackrel{\mathbb{\Omega}}{\Omega}$ of cords and tubules of small hyperchromatic, i cuboidal or columnar cells. Clear cell change was seen in one case. In the stroma there were spindle cells, round cells, and occasional giant cells. Mitoses were numerous. Merging of epithelial $\stackrel{\circ}{\mathcal{L}}$ and mesenchymal elements was seen in the $\vec{x}$ tumours from the two men. It was concluded by $\underset{\omega}{\dot{\omega}}$ the authors that these tumours showed the $\vec{i}$ characteristics of both carcinosarcoma and of blastoma, and they were classified as "transitional" స్ tumours.

All three cases were considered cperable. One $\stackrel{\vec{T}}{\rightarrow}$ was treated by lobectomy and the other two by $O$ pneumonectomy. The patient who underwent lobectomy died 18 months later with hepatic and osseous metastases, six months after developing a recurrence in the operation scar and pleura. A biopsy of the recurrent tumour showed, as in the present case, a pleomorphic spindle ccll tumour with occasional giant cells. No epithelial component was seen. One of the patients who had a pneumonectomy died postoperatively of respiratory failure, and the other one, the woman was lost to follow-up at three months.

The case we describe is a further example of the transitional type of tumour. There are areas of well-differentiated squamous carcinoma, which are a feature of the more usual type of carcinosarcoma. However, the fcci of tubular and cleftlike differentiation and also the solid cords of anaplastic epithelial cells are much more in keeping with a pulmonary blastoma. The widely diverse appearance of the stroma is of interest and has not been described previously in mixed malignant tumours of the lung. As we have seen, however, in individual neoplasms the mesenchymal element has been reported as showing differentiation towards chondroid, osseous, fibrous, or muscular tissue. There does not appear to be any reason why such a stroma should not undergo metaplasia in several different directions in the same tumour.

Any discussion of the histogenesis of mixed malignant tumours of the lung must be speculative. It has been suggested that carcinosarcomas arise as a result of simultaneous development of a carcinoma and sarcoma (Bergmann et al, 1951; Diaconită, 1975), from malignant change in a hamartoma (Prive et al, 1961), or malignant or reactive metaplasia in the stroma of a carcinoma (Herxheimer and Reinke, 1912; Harvey and Hamilton, 1935; Drury and Stirland, 1959: Jenkins, 
1968). The similarity between fetal lung and pulmonary blastoma, and Waddell's (1949) theory of the mesenchymal derivation of peripheral lung, led Spencer (1961) to suggest that such tumours arose from pluripotential mesenchyme, as in nephroblastoma. The occurrence in an older age group was explained by the continuing postnatal development of the lung. Other authors (Stackhouse et al, 1969; McCann et al, 1976). however, regarded blastomas as variants of carcinosarcoma and, furthermore, later studies have made Waddell's theory untenable (Fung et al, 1977).

The rarity of this group of tumours precludes adequate study of the natural history by individual pathologists and clinicians. From published reports, however, it would appear that most are operable at the time of presentation, and lobectomy or pneumonectomy is the treatment of choice. Carcinosarcomas and transitional tumours have a poor prognosis, whereas some pulmonary blastomas behave in a much more indolent fashion, and cases of long survival are on record.

We are grateful to $\mathrm{Mr} \mathbf{M}$ Chard and the technical staff of the Histopathology Department, East Birmingham Hospital, for their photographic help, and to Mrs Ruth Fry for typing the manuscript. Dr Saunders is in receipt of a research grant from Messrs Searle.

\section{References}

Barnard, W G (1952). Embryoma of lung. Thorax, 7, 299-301.

Bauermeister, D E, Jennings, E R, Beland, A H, and Judson, H A (1966). Pulmonary blastoma, a form of carcinosarcoma: Report of a case of 24 hours' duration without treatment. American Journal of Clinical Pathology, 46, 322-329.

Bergmann, M, Ackerman, L V, and Kemler, R L (1951). Carcinosarcoma of the lung. Cancer, 4, 919929.

Bull, J C, and Grimes, O F (1974). Pulmonary carcinoma. Chest, 65, 9-12.

Chaudhuri, M R (1971). Bronchial carcinosarcoma. Journal of Thoracic and Cardiovascular Surgery, 61, 319-323.

Davis, P W, Briggs, J C, Seal, R M E, and Storring, F K (1972). Benign and malignant mixed tumours of the lung. Thorax, 27, 657-673.

Diaconită, G (1975). Bronchopulmonary carcinosarcoma. Thorax, 30, 682-686.

Drury, R A B, and Stirland, R M (1959). Carcinosarcomatous tumours of the respiratory tract. Journal of Pathology and Bacteriology, 77, 543-554.

Fung, C H, Lo, J W, Yonan, T N, Milloy, F J, Hakami, M M, and Changus, C W (1977). Pulmonary blastoma. An ultrastructural study with a brief review of literature and a discussion of pathogenesis. Cancer, 39, 153-163.

Harvey, W F, and Hamilton, T D (1935). Carcinosarcoma: Study of the microscopic anatomy and the meaning of a peculiar cancer. Edinburgh Medical Journal, 42, 337-378.

Henry, K, and Keal, E E (1966). Pulmonary blastoma with a striated muscle component. British Journal of Diseases of the Chest, 60, 87-92.

Herxheimer, G, and Reinke, G (1912). Carcinoma sarcomatodes (pathologie des krebses). Ergebnisse der Allegemeinen Pathologie und Pathologischen Anatomie des Menschen und der Tiere, 16, 280-282.

Iverson, R E, and Straehley, C J (1973). Pulmonary blastoma, long-term survival of a juvenile patient. Chest, 63, 436-440.

Jenkins, B J (1968). Carcinosarcoma of the lung: Report of a case and review of the literature. Journal of Thoracic and Cardiovascular Surgery, 55, 657662.

Kakos, G S, Williams, T E, Assor, D, and Vasko, J S (1971). Pulmonary carcinosarcoma. Etiologic, therapeutic and prognostic considerations. Journal of Thoracic and Cardiovascular Surgery, 61, 777783.

Karcioglu, Z A, and Someren, A O (1974). Pulmonary blastoma. American Journal of Clinical Pathology, 61, 287-295.

Kern, W H, and Stiles, Q R (1970). Pulmonary blastoma. Journal of Thoracic and Cardiovascular surgery, 72, 801-808.

Kika (1908). Cited by Herxheimer and Reinke.

Ludwigsen, E (1977). Endobronchial carcinosarcoma. Virchows Archives; A: Pathological Anatomy and Histology, 373, 293-302.

Marsden, H B, and Scholtz, C L (1976). Pulmonary blastoma. Virchows Archives; A: Pathological Anatomy and Histology, 372, 161-165.

McCann, M P, Fu, Y-S, and Kay, S (1976). Pulmonary blastoma. A light and electron microscopic study. Cancer, 38, 789-797.

Moore, T C (1961). Carcinosarcoma of the lung. Surgery, 50, 886-893.

Pacharee, P, and Parichatikanond, P (1972). Pulmonary blastoma-A case report in an infant and review of the literature. Journal of the Medical Association of Thailand, 55, 43-48.

Parker, J C, Payne, W S, and Woolner, L B (1966). Pulmonary blastoma (embryoma): Report of two cases. Journal of Thoracic and Cardiovascular Surgery, 51, 694-699.

Prive, L, Tellem, M, Meranze, D R, and Chodoff, R D (1961). Carcinosarcoma of the lung. Archives of Pathology (Chicago), 72, 351-357.

Rao, K M, Gupta, R P, Das, P B, John, S, and Walter, A (1974). Pulmonary blastoma: A case report. Thorax, 29, 138-141.

Razzuk, M A, Urschel, H C, Race, G J, Arndt. J H, and Paulson, D L (1971). Carcinosarcoma of the lung. Journal of Thoracic and Cardiovascular Surgery, 61, 541-546. 
Saltykow, S (1914). Cited by Kakos et al.

Saphir, O, and Vass, A (1938). Carcinosarcoma. American Journal of Cancer, 33, 331-361.

Spencer, H (1961). Pulmonary blastomas. Journal of Pathology and Bacteriology, 82, 161-165.

Stackhouse, E M, Harrison, E G, and Ellis, F H (1969). Primary mixed malignancies of lung: carcinosarcoma and blastoma. Journal of Thoracic and Cardiovascular Surgery, 57, 385-399.

Waddell, W R (1949). Organoid differentiation of the fetal lung: A histologic study of the differentiation of mammalian fetal lung in utero and in transplants. Archives of Pathology (Chicago), 47, 227-247.

Weaver, P C, Branfoot, A C, and Hargrove, R L (1971). An endobronchial carcinosarcoma treated by lobectomy. Journal of Thoracic and Cardiovascular Surgery, 61, 300-303.

Requests for reprints to: Dr C W Edwards, Department of Pathology, East Birmingham Hospital, Birmingham B9 5ST. 